ORIGINAL ARTICLE

\title{
Increased Uric Acid and Life Style Factors Associated with Metabolic Syndrome in Thais
}

\author{
Suwit Klongthalay ${ }^{1}$, Kanjana Suriyaprom ${ }^{*}$
}

\begin{abstract}
OPEN ACCESS
Citation: Suwit Klongthalay, Kanjana Suriyaprom. Increased uric acid and life style factors associated with metabolic syndrome in Thais. Ethiop J Health Sci.2020;30(2):199.

doi:http://dx.doi.org/10.4314/ejhs.v30 i2.7

Received: October 3, 2019

Accepted: November 1, 2019

Published: March 1, 2020

Copyright: (C2020 Klongthalay S., et al.

This is an open access article distributed under the terms of the Creative Commons Attribution License, which permits unrestricted use, distribution, and reproduction in any medium, provided the original author and source are credited.

Funding: Faculty of Medical

Technology, Rangsit University

Competing Interests: The authors

declare that this manuscript was approved

by all authors in its form and that no competing interest exists.

Affiliation and Correspondence:

${ }^{1}$ Faculty of Medical Technology,

Rangsit University, Phaholyothin Road,

Pathumthani 12000, Thailand

*Email: kanjana.su@rsu.ac.th
\end{abstract}

\section{ABSTRACT}

BACKGROUND: The prevalence of metabolic syndrome (MS) has been continually increasing in developing countries especially in Thailand. Although insulin resistance and central obesity are initially considered as significant risk factors, the other causal factors leading to the development of MS continue to challenge the investigators. The aims of this study were to evaluate the prevalence of MS in Pathum Thani province, Thailand and to investigate the relationship between MS and risk factors. METHODS: This cross-sectional study was performed with 202 Thai volunteers. Anthropometric-biochemical variables and blood pressures in each subject were measured.

RESULTS: Almost one-third (32.7\%) of the participants were diagnosed with MS based on the harmonized criteria, and one of the most significant risk factors is the elevated blood pressure. Weight, BMI, waist and hip circumferences, waist-hip ratio, blood pressure, glucose, triglycerides and uric acid were significantly higher in subjects with MS subjects. However, HDL-C levels were significantly lower in subjects with MS, compared to subjects without MS $(p<0.001)$. The results of regression model after adjustment for age and gender showed that the increased serum uric acid level $(O R=1.31,95 \% C I:=1.04-1.66)$, cigarette smoking $(O R=3.72,95 \% C I:=1.51-9.15)$ and physical activity $(O R=0.36$, 95\%CI: $=0.19-0.67)$ were significantly related to $M S$.

CONCLUSIONS: These findings suggest that the decrease of uric acid level, the promotion of physical activity and smoking cessation may decrease the risk of developing MS among Thais.

KEYWORDS: Metabolic Syndrome, Life Style, Uric Acid

\section{INTRODUCTION}

Metabolic syndrome (MS) is a public health problem that has reached epidemic proportions with a rapidly increasing worldwide prevalence and for the adult population is estimated to be about 20 to $25 \%$ (1). There were evidences showing that MS is a clinical constellation comprising risk factors associated with increased risk of cardiovascular diseases (CVDs) by 2-fold and the risk of developing Type 2 diabetes by 5 -fold $(2,3)$. Thus, the clustering symptoms 
leading to Type 2 diabetes and CVDs are typified as the MS that is now considered to impact on global healthcare systems and financial plans. Thailand has gone through a period of epidemic transition, and many metabolic risk factors: obesity, dyslipidemia, insulin resistance, and hypertension, are now common among the Thai population (4). Obesity, especially visceral fat, remains an important link among the components of MS and the prevalence of obesity is rapidly growing in low- and middle-income countries including Thailand. The central region of Thailand has the highest prevalence of obesity for both males $(38.8 \%)$ and females (49.4\%), compared with other regions: the southern region $(27.4 \%$ and $44.7 \%)$, the northern region $(27.5 \%$ and $36.3 \%)$ and the north-eastern region $(22.5 \%$ and $39.1 \%)$ (5). Despite of the importance of MS in the context of noncommunicable diseases in Thailand, especially in the central region, information regarding the importance of the prevalence of MS and its determinants is scarce. The causal factors leading to the development MS continue to challenge the researchers. Therefore, this study aimed to evaluate the prevalence of MS in the population of Pathum Thani Province, the central region of Thailand and to investigate the relationship between MS and risk factors.

\section{MATERIALS AND METHODS}

Study subjects: The study was performed with 202 Thai volunteers from the population in a suburban community located at the Lak-Hok in Pathum Thani Province, Thailand, aged between 20 to 80 years old. This was a cross-sectional, populationbased study with simple random sampling between November 2017 and January 2019 with the objective to estimate the prevalence of MS and associated factors in the adult population. The subjects were invited to the Medical Technology Clinic of Rangsit University for laboratory examinations. All volunteers were interviewed by using a questionnaire, regarding lifestyle pattern, and medical health history. Participants who reported consuming alcohol at least once per week for more than 6 months were defined as drinkers. Participants who had smoked at least one cigarette per day for more than 6 months were defined as smokers. For Leisure-time physical activity, participants were asked whether they had engaged in regular exercise or sports (at least once a week for 3 months continuously). The exclusion criteria of this study included pregnancy, severe degenerative diseases, mental deficiency, stroke, cancer, kidney diseases, gout, and bedridden patients. MS was defined using the harmonized definition (6) and required at least three of the following:

- Raised waist circumference: $>90 \mathrm{~cm}$ in Asian men and $>80 \mathrm{~cm}$ in Asian women

- Raised blood pressure: systolic blood pressure $\geq 130 \mathrm{mmHg}$ or diastolic blood pressure $\geq 85 \mathrm{mmHg}$, or current antihypertensive medication

- Raised fasting plasma glucose: $\geq 100$ $\mathrm{mg} / \mathrm{dl}$

- Raised triglycerides (TG) levels: $\geq 150$ $\mathrm{mg} / \mathrm{dl}$

- Reduced high-density lipoprotein cholesterol (HDL-C): $<40 \mathrm{mg} / \mathrm{dl}$ in men and $<50 \mathrm{mg} / \mathrm{dl}$ in women

This study was conducted under the principles of the Declaration of Helsinki and the protocol was approved by the Ethics Committee of Rangsit University (RSEC 11/2560). All participants agreeing to participate signed a consent form.

Measurement of biochemical markers: Five milliliters of overnight fasting venous blood was taken from each subject. Serum was used to assay biochemical variables. For example, total cholesterol, triglycerides, HDL-cholesterol, LDLcholesterol, uric acid, total protein, and albumin. $\mathrm{NaF}$ blood was used to assay glucose, and these biochemical markers were measured by using COBAS INTEGRA ${ }^{\circledR} 400$ plus analyzer, Roche Diagnostics Ltd., Switzerland.

Anthropometric and blood pressure measurements: Anthropometric measurements comprising weight, height, waist circumferences, and hip circumference, were recorded. The body weight of each individual dressed in light clothing was measured using a carefully calibrated beam balance (Detecto $\left.{ }^{\circledR}\right)$. The height of each individual was measured using a vertical-measuring rod. Waist circumference (WC) and hip circumference (HC) were calculated for waist-hip ratio $(\mathrm{W} / \mathrm{H}$ ratio). The body mass index (BMI) was expressed as weight $(\mathrm{kg}) /$ height $\left(\mathrm{m}^{2}\right)$. The participants were

DOI: http://dx.doi.org/10.4314/ejhs.v30i2.7 
classified according to their BMI as followings: normal weight $\left(\mathrm{BMI}<23.00 \mathrm{~kg} / \mathrm{m}^{2}\right)$, overweight $\left(\mathrm{BMI} \geq 23.00-24.99 \mathrm{~kg} / \mathrm{m}^{2}\right)$ and obese $(\mathrm{BMI} \geq 25.00$ $\mathrm{kg} / \mathrm{m}^{2}$ ) (7). Blood pressure (BP) and pulse rate were measured by a nurse after 5 to 10 minutes' rest in the sitting position.

Statistical analysis: Statistics analyses were performed using SPSS for Windows version 17.0 (SPSS, Chicago, IL). The median and 95\% confidence interval (C.I.) were calculated. The difference between the two groups was compared by using the Mann-Whitney U-Wilcoxon Rank Sum W test. Relationship between MS and various parameters was tested using Chi-square test. The Minitab statistical computer program was used to calculate the odds ratio (OR). A p-value $<0.05$ was considered statistically significant.

\section{RESULTS}

This cross-sectional study enrolled 202 participants with mean age $53.2 \pm 3.2$ years; $37.1 \%$ and $62.9 \%$ of all participants were males and females, respectively. Obesity and overweight rates in our study were $43.1 \%$ and $17.3 \%$, respectively. Demographic and lifestyle characteristics of the studied population are shown in Table 1. More than thirty percent $(32.7 \%)$ of the participants were diagnosed with MS based on the harmonized criteria, and the common risk factor was elevated blood pressure (Table 2).

Table 1: Demographic, anthropometric and lifestyle characteristics of the studied population

\begin{tabular}{lll}
\hline Characteristics & & N (\%) \\
\hline Gender & Male & $75(37.1)$ \\
& Female & $127(62.9)$ \\
Education (schooling & $<12$ years & $119(58.9)$ \\
years) & $\geq 12$ years & $83(41.1)$ \\
BMI & Normal-weight & $80(39.6)$ \\
& Overweight & $35(17.3)$ \\
Physical activity & Obese & $87(43.1)$ \\
& Inactive & $75(37.1)$ \\
Cigarette smoking & Active & $127(62.9)$ \\
& No & $165(81.7)$ \\
Alcohol consumption & Yes & $37(18.3)$ \\
& No & $154(76.2)$ \\
\hline
\end{tabular}

Table 2: Prevalence of MS and its components

\begin{tabular}{lc}
\hline \multirow{2}{*}{ Metabolic syndrome components } & $\begin{array}{c}\text { Total subjects } \\
(\mathbf{N}=\mathbf{2 0 2})\end{array}$ \\
\cline { 2 - 2 } & $\mathbf{N ~ ( \% )}$ \\
\hline Central obesity & $111(55.0 \%)$ \\
Elevated glucose & $64(31.7 \%)$ \\
Elevated TG & $59(29.2 \%)$ \\
Reduced HDL-C & $52(25.7 \%)$ \\
High blood pressure & $120(59.4 \%)$ \\
Metabolic syndrome & $66(32.7 \%)$ \\
\hline
\end{tabular}

HDL-C, high-density lipoprotein cholesterol 
Anthropometric and biochemical data of the groups with MS (66 subjects) and without MS (136 subjects) are shown in Table 3. Age, weight, BMI, WC, HC, waist-hip ratio, blood pressure, glucose, TG and uric acid were significantly higher in subjects with MS subjects than in that without MS $(p<0.01)$. Meanwhile, HDL-C levels of subjects with MS were significantly lower than subjects without MS $(p<0.01)$. The prevalence of MS according to age was showed that there was significantly different among age groups $(p<0.05)$ and rising with aging years. The percentage of subjects with MS in each age group was: 20-39 years $(17.2 \%$; $5 / 29), 40-49$ years $(25.0 \% ; 8 / 32)$, $50-59$ years $(31.7 \% ; 26 / 82)$ and $\geq 60$ years $(45.8 \%$;
27/59). Table 4 shows the risk factors are related to MS. Our results showed that lower secondary education $(\mathrm{OR}=1.99, \mathrm{p}<0.05)$, cigarette smoking $(\mathrm{OR}=2.65, \quad \mathrm{p}<0.01), \quad$ and physical activity $(\mathrm{OR}=0.37, \mathrm{p}<0.01)$ were associated with MS. The proportions of cigarette smoking and physical activity between the MS group and the non-MS group were $28.8 \%$ vs $13.2 \%, 47.0 \%$ vs $70.6 \%$, respectively. About $30.3 \%$ in the MS group and $46.3 \%$ in the non-MS group had completed secondary level education or higher. The correlation of uric acid with components associated with metabolic syndrome is shown in Table 5.

Table 3: Comparison of anthropometric, biochemical variables and age between subjects with and without $\mathrm{MS}$

\begin{tabular}{|c|c|c|c|}
\hline \multirow[t]{2}{*}{ Variables } & $\begin{array}{c}\text { Subjects without MS } \\
(\mathrm{n}=136)\end{array}$ & $\begin{array}{c}\text { Subjects with MS } \\
(\mathrm{n}=66)\end{array}$ & \multirow[t]{2}{*}{ p-value } \\
\hline & Mean (SD) & Mean (SD) & \\
\hline Age (years) & $51.7(14.2)$ & $56.2(10.4)$ & $0.011 *$ \\
\hline Weight $(\mathrm{kg})$ & $59.4(10.5)$ & $68.2(11.4)$ & $<0.001 * *$ \\
\hline Height (cm) & $159.4(8.2)$ & $158.9(8.9)$ & 0.669 \\
\hline BMI $\left(\mathrm{kg} / \mathrm{m}^{2}\right)$ & $23.3(3.4)$ & $26.9(3.4)$ & $<0.001 * *$ \\
\hline $\mathrm{WC}(\mathrm{cm})$ & $82.0(10.0)$ & $93.2(7.3)$ & $<0.001 * *$ \\
\hline $\mathrm{HC}(\mathrm{cm})$ & $95.4(7.1)$ & $100.8(8.4)$ & $<0.001 * *$ \\
\hline Waist-hip ratio & $0.86(0.07)$ & $0.93(0.05)$ & $<0.001 * *$ \\
\hline Systolic BP (mmHg) & $132.0(17.0)$ & $142.0(18.0)$ & $<0.001 * *$ \\
\hline Diastolic BP (mmHg) & $78.0(9.0)$ & $82.0(11.0)$ & $0.002 * *$ \\
\hline Pulse rate (beats/min) & $78.0(10.0)$ & $80.0(10.0)$ & 0.147 \\
\hline Glucose (mg/dl) & $88.8(10.6)$ & $116.8(17.2)$ & $<0.001 * *$ \\
\hline $\mathrm{TC}(\mathrm{mg} / \mathrm{dl})$ & $212.9(45.3)$ & $208.8(44.9)$ & 0.544 \\
\hline $\mathrm{TG}(\mathrm{mg} / \mathrm{dl})$ & $110.3(39.0)$ & $171.9(30.0)$ & $<0.001 * *$ \\
\hline HDL-C (mg/dl) & $63.4(15.1)$ & $46.7(13.7)$ & $<0.001 * *$ \\
\hline LDL-C (mg/dl) & $141.7(43.0)$ & $137.7(41.9)$ & 0.521 \\
\hline Total protein $(\mathrm{g} / \mathrm{dl})$ & $7.6(0.4)$ & $7.7(0.4)$ & 0.224 \\
\hline Albumin (g/dl) & $4.0(0.3)$ & $4.0(0.2)$ & 0.915 \\
\hline Uric acid (mg/dl) & $4.8(1.4)$ & $5.4(1.4)$ & $0.009 * *$ \\
\hline
\end{tabular}

BMI, body mass index: WC, waist circumference: HC, hip circumference: BP, blood pressure: HDL-C, high-density lipoprotein cholesterol: LDL-C, low-density lipoprotein cholesterol: TG, triglyceride: TC, total cholesterol.

$*=\mathrm{p}<0.05, * *=\mathrm{p}<0.01$ by using Student's t-test 
Table 4: Risk factors related to MS

\begin{tabular}{|c|c|c|c|c|c|}
\hline Parameters & & $\begin{array}{c}\text { Subjects with } \\
\text { MS } \\
\text { N=66 }\end{array}$ & $\begin{array}{c}\text { Subjects } \\
\text { without MS } \\
\text { N=136 }\end{array}$ & $\begin{array}{l}\text { Odds ratio } \\
(95 \% \mathrm{CI})\end{array}$ & p-value \\
\hline \multirow[t]{2}{*}{ Gender } & Female & $39(59.1 \%)$ & $88(64.7 \%)$ & 1.27 & 0.439 \\
\hline & Male & $27(40.9 \%)$ & $48(35.3 \%)$ & $(0.69-2.32)$ & \\
\hline \multirow{2}{*}{$\begin{array}{l}\text { Education (schooling } \\
\text { years) }\end{array}$} & $<12$ years & $46(69.7 \%)$ & $73(53.7 \%)$ & 1.99 & $0.030^{*}$ \\
\hline & $\geq 12$ years & $20(30.3 \%)$ & $63(46.3 \%)$ & $(1.06-3.70)$ & \\
\hline \multirow[t]{2}{*}{ Physical activity } & Yes & $31(47.0 \%)$ & $96(70.6 \%)$ & 0.37 & $0.001 * *$ \\
\hline & No & $35(53.0 \%)$ & $40(29.4 \%)$ & $(0.20-0.68)$ & \\
\hline \multirow[t]{2}{*}{ Cigarette smoking } & Yes & $19(28.8 \%)$ & $18(13.2 \%)$ & 2.65 & $0.007 * *$ \\
\hline & No & $47(71.2 \%)$ & $118(86.8 \%)$ & $(1.28-5.49)$ & \\
\hline \multirow[t]{2}{*}{ Alcohol consumption } & Yes & $14(21.2 \%)$ & $34(25.0 \%)$ & 0.81 & 0.553 \\
\hline & No & $52(78.8 \%)$ & $102(75.0 \%)$ & $(0.40-1.64)$ & \\
\hline
\end{tabular}

$*=\mathrm{p}<0.05, * *=\mathrm{p}<0.01$ by using Pearson chi-square, OR- Odds ratio: $95 \% \mathrm{CI}, 95 \%$ confidence interval

Serum uric acid level was positively correlated with BMI, WC, Waist-hip ratio, glucose and TG levels, but correlated negatively with HDL-C. The possible associations between MS and education, alcohol drinking, cigarette smoking, physical activity and uric acid, are shown in Table 6. The results of regression model after adjustment for age and gender showed that for every $1 \mathrm{mg} / \mathrm{dl}$ elevation in the serum uric acid level, the OR for developing MS had increased approximately 1.31-fold (95 \%CI: 1.04-1.66), and cigarette smoking was 3.72 (95\%CI: $1.51-9.15)$ times more likely to have MS. Meanwhile, physical activity was related to lower OR of the MS $(\mathrm{OR}=0.36,95 \% \mathrm{CI}=0.19-0.67)$.

Table 5: Correlation of uric acid with components associated with MS. $(n=202)$

\begin{tabular}{lcc}
\hline Parameters & Correlation Coefficient & p-value \\
\hline Glucose & 0.161 & $0.020^{*}$ \\
TG & 0.358 & $<0.001^{* *}$ \\
HDL-C & -0.397 & $<0.001^{* *}$ \\
Systolic BP & 0.028 & 0.749 \\
Diastolic BP & 0.079 & 0.265 \\
BMI & 0.316 & $<0.001^{* *}$ \\
WC & 0.357 & $<0.001^{* *}$ \\
Waist-hip ratio & 0.344 & $<0.001^{* *}$ \\
\hline
\end{tabular}

$*=\mathrm{p}<0.05$ by Spearman's rank correlation (2-tailed)

$* *=\mathrm{p}<0.01$ by Spearman's rank correlation (2-tailed) 
Table 6: OR (95\% CI) for predictors of MS, derived from logistic regression models with and without control for other factors $(n=202)$

\begin{tabular}{ccc}
\hline Predictors & $\begin{array}{c}\text { Unadjusted OR } \\
\mathbf{( 9 5 \% C I )}\end{array}$ & $\begin{array}{c}\text { Adjusted OR }^{\mathbf{a}} \\
\mathbf{( 9 5 \% C I )}\end{array}$ \\
\hline Education & $1.99 *(1.06-3.70)$ & $1.77(0.93-3.39)$ \\
(<12 schooling years) & $0.81(0.40-1.64)$ & $0.79(0.37-1.67)$ \\
Alcohol consumption & $2.65 *(1.28-5.49)$ & $3.72 * *(1.51-9.15)$ \\
Cigarette smoking & $0.37 * *(0.20-0.68)$ & $0.36 * *(0.19-0.67)$ \\
Exercise activity & $1.29 *(1.06-1.59)$ & $1.31 *(1.04-1.66)$ \\
Uric acid (mg/dl) &
\end{tabular}

OR-Odds ratio: $95 \% \mathrm{CI}, 95 \%$ confidence interval, $*=\mathrm{p}<0.05, * *=\mathrm{p}<0.01$ by using logistic regression.

${ }^{\text {a }}$ adjusted for age and sex

\section{DISCUSSION}

MS is the major health problem which is increasing worldwide. In the present study, the overall prevalence of MS among participants in a suburban community in Patumthani province was $32.7 \%$ based on the harmonized criteria. Our finding was concordant with the prevalence of MS in the InterASIA study among Thai adults from four regions of Thailand including the capital Bangkok (32.6\%) (8) and Thai participants in Klong Luang, Pathum Thani Province (36.5\%) (9). Its prevalence in Khon Kaen $(15.0 \%)$, a northeast province of Thailand, was lower than the our study (10). Moreover, the prevalence of MS in this finding is in line with the countries of the Asia-Pacific region ranged from $11 \%$ to $40 \%$ (11), such as $27.9 \%$ in Malaysia (12) and 33\% in India (13). However, the difference in the prevalence may be due to the differences in the race and MS definition, especially in the cut-off points of waist circumference and fasting glucose level. Additionally, the difference in participants' lifestyle may contribute to distinct prevalence levels; Pathum Thani Province, a neighboring province of the capital city of Thailand, has gone through a period of epidemic transition, and risk factors associated with MS such as obesity plus a sedentary lifestyle are commonly found in this population (9). Furthermore, this study found that the prevalence of MS was age-dependent with the highest prevalence in participants with age of $\geq 60$ years old. This finding was in accordance with other studies $(14,15)$ because many predisposing conditions which rising in the MS prevalence during aging, such as insulin resistance, obesity and hypertension (15). Hypertension was the major component of MS in our study followed by central obesity, and this finding was similar to a comprehensive review of Katsimardou et al. that hypertension was present in almost $80 \%$ of patients with MS (16). Regarding hypertension in MS, the pathophysiologic mechanism had been proposed that insulin resistance can stimulate the sympathetic nervous system and decrease nitric oxide production, contributing to increases in blood pressure $(17,18)$. Hypertension is the most common modifiable risk factor for cardiovascular disease (CVD) including coronary heart disease, myocardial infarction, heart failure, and stroke (19). Therefore, MS patients have a higher susceptibility for cardiovascular problems.

The underlying cause of MS is visceral obesity, and adipose tissue is a major organ that has plentiful activity of xanthine oxidoreductase (XOR) and the role of adipose tissue per se in the production of uric acid with a special focus on $\mathrm{XOR}$, an enzyme known to catalyze purines, such as xanthine and hypoxanthine, to uric acid $(20,21)$. The explanation of this relation may be associated with hypoxia of obese adipose tissue that hypoxicinduced increase in XOR activity has been revealed in several studies $(20,22,23)$, and hypoxia also induces dysfunction of adipose tissue, such as dysregulation of adipocytokines. In agreement with Tsushima et al. (20), our data found positive correlation of uric acid levels with obesity indices including WC and BMI. A study in identical twins also reported that serum uric acid was found to be significantly correlated with BMI even after adjusting for genetic and family environment 
factors (24). Moreover, the present study revealed the association between serum uric acid and TG; this relation is in line with previous studies $(25,27)$. There are some potential mechanisms for this relationship that TG synthesis accelerates the de novo synthesis of ribose-5-phosphate to phosphoribosyl pyrophosphate (PPRP) through the common metabolic pathway of NADP-NADPH, and as a result of increasing uric acid production (28). Our results also showed that serum uric is correlated with glucose, and this finding has been reported in some previous studies $(27,29)$. The potential mechanism is that increased uric acid levels can block the activation of AMPK, leading to the translocation of the transducer of regulated CREB activity 2 (TORC2) to the nucleus and the transcription of phosphoenolpyruvate carboxykinase (PEPCK) and glucose-6phosphatase (G6Pc) that stimulate de novo production of glucose (30). Therefore, our data provided confirmation of findings on association between serum uric acid and components of MS.

The result of logistic regression analyses showed that after adjusted with age and sex, cigarette smoking and hyperuricemia were risk factor whereas physical activity was a protective factor of MS. Our study revealed that the person with high serum uric acid had 1.31 times higher in the odd of MS development, and this was consistent with the studies in Taiwan (31) and Iran (32). However, the precise biological mechanisms underlying the relationship between serum uric acid and developing MS remain unclear. Zhu et al. found that increased uric acid level may directly inhibit insulin receptor substrate-1 (IRS-1) and Akt insulin signaling and induce insulin resistance, which is the key pathophysiology of MS (33). Although TG synthesis stimulates the uric acid production, Kuwabara et al. (34) found that hyperuricemia is the risk factor for developing hypertriglyceridemia. Oxidative stress may be responsible for uric acid mediatedhypertriglyceridemia via citrate accumulation and stimulation of ATP citrate lyase leading to increased fat production (35). Additionally, our study revealed that hypertension is the major component of MS, and the study of Loeffler et al. found that hyperuricemia is the risk factor of hypertension (36). The mechanism for uric acid mediated hypertension could be described by the induction of endothelial dysfunction (37) and activation of the renin-angiotensin system (38). Therefore, it has been suggested that serum uric acid might be an additional component of MS.

Our study has shown that low education level was prone to MS occurrence; similar data were reported by Kim et al. (39). A study done by Silventoinen et al. (40) also found that the prevalence of MS was less in university education level. These data may partly explain by the impact of education that has the potential to improve the dietary habits and lifestyle while reducing incidences of MS $(39,41)$. Moreover, the result of the present study is consistent with results from a meta-analysis of Sun et al. that cigarette smoking is associated with developing MS (42). Bergman et al. indicated that nicotine exposure had significantly increased IRS- $1^{\text {ser636 }}$ phosphorylation and decreased insulin sensitivity (43). Serine phosphorylation of many sites on (IRS-1), including ser636 decreases IRS-1 tyrosine phosphorylation and insulin-stimulated glucose uptake (44). These data suggest that inhibition of insulin signaling may be an important mechanism responsible for cigarette smoking-induced insulin resistance, and many features of the MS are related to insulin resistance. Furthermore, smoking can increase blood pressure, waist circumference, triglycerides, and reduce HDL-C (42). In the present study, we found that leisure-time physical activity was a protective factor for reducing MS in Thais. This result was consistent with a metaanalysis of Roomi et al. (41) and in Taiwanese workers (45). Huang et al. revealed that a high level of physical activity had lower risks of MS including abdominal adiposity and hypertriglyceridemia (45). The underlying mechanisms for the advantages of high-intensity exercise may involve in improved lipid biogenesis in the adipose tissues and liver (46) and in increased HDL-C by stimulating expression of post-heparin lipoprotein lipase (47). Hence, the MS may be prevented by changing the lifestyle to lower the risk factor including frequent exercise and smoking cessation. This information derived from Thais should be more applicable to our

DOI: http://dx.doi.org/10.4314/ejhs.v30i2.7 
society and other countries to improve the quality of life and reduce the risk of various noncommunicable diseases related to MS.

The limitations of our study are the small sample size of both groups and the lack of diabetes indices including insulin and HOMA-IR value for evaluation of insulin resistance. Therefore, further studies are required on larger cohorts with different ethnic groups.

In summary, the overall prevalence of MS in a suburban community in Pathum Thani Province, Thailand, was $32.7 \%$; hypertension was the major component of MS. The increased serum uric acid level, cigarette smoking and lack of physical activity were significantly associated with developing MS in Thais.

\section{ACKNOWLEDGMENTS}

The authors wish to express their sincere thanks to all volunteers and staff of the Faculty of Medical Technology, Rangsit University, for their cooperation in carrying out this research. We also thank the Center of Translation, Faculty of Liberal Arts, Rangsit University, for proofreading this manuscript. The project was supported by funds from the Faculty of Medical Technology, Rangsit University, Thailand.

\section{REFERENCES}

1. International Diabetes Federation. IDF Consensus Worldwide Definition of the Metabolic Syndrome [cited 2019 Jun 15]. Available from: https://www.idf.org/elibrary/consensus-statements/60-idfconsensusworldwide-definitionof-the-metabolicsyndrome.

2. Franklin SS. Hypertension in the metabolic syndrome. Metab Syndr Relat Disord. 2006;4(4):287-98.

3. Grundy SM, Cleeman JI, Daniels SR, Donato KA, Eckel RH, Franklin BA, et al. Diagnosis and management of the metabolic syndrome: an American Heart Association/National Heart, Lung, and Blood Institute Scientific Statement. Circulation. 2005;112(17):273552.

4. Aekplakorn W, Kessomboon P, Sangthong R, Chariyalertsak S, Putwatana P, Inthawong R, et al. Urban and rural variation in clustering of metabolic syndrome components in the Thai population: results from the fourth National Health Examination Survey 2009. BMC Public Health. 2011;11(1):854.

5. Teerawattananon Y, Luz A. Obesity in Thailand and Its Economic Cost Estimation. Asian Development Bank Institute; 2017.

6. Alberti KG, Eckel RH, Grundy SM, Zimmet PZ, Cleeman JI, Donato KA, et al. Harmonizing the metabolic syndrome: a joint interim statement of the International Diabetes Federation Task Force on Epidemiology and Prevention; National Heart, Lung, and Blood Institute; American Heart Association; World Heart Federation; International Atherosclerosis Society; and International Association for the Study of Obesity. Circulation. 2009;120(16):1640-5.

7. The Western Pacific Region, World Health Organization, International Associates for the Study of Obesity, International Obesity Task Force. The Asia-Pacific perspective : redefining obesity and its treatment. Melbourne: Health Communications Australia Pty Ltd; 2000.

8. Aekplakorn W, Chongsuvivatwong V, Tatsanavivat P, Suriyawongpaisal P. Prevalence of metabolic syndrome defined by the International Diabetes Federation and National Cholesterol Education Program criteria among Thai adults. Asia Pac J Public Health. 2011;23(5):792-800.

9. Yuenyongchaiwat K, Pipatsitipong D, Sangprasert P. The prevalence and risk factors of metabolic syndrome a suburban community in Pathum Thani province, Thailand. Songklanakarin J. Sci. Technol. 2017;39(6):787-92.

10. Pongchaiyakul C, Nguyen TV, Wanothayaroj E, Karusan N, Klungboonkrong V. Prevalence of metabolic syndrome and its relationship to weight in the Thai population. $J$ Med Assoc Thai. 2007;90(3):459-67.

11. Ranasinghe $\mathrm{P}$, Mathangasinghe Y, Jayawardena R, Hills AP, Misra A. Prevalence and trends of metabolic syndrome among adults in the asia-pacific region: a systematic review. BMC Public Health. 2017;17(1):101. 
12. Chee H, Hazizi A, Barakatun Nisak M, Mohd Nasir M. Metabolic risk factors among government employees in Putrajaya, Malaysia. Sains Malays. 2014;43(8):1165-74.

13. Srilakshmi P, Swetha D, Bhaskar M, Rambabu K, Madhulatha M. Prevalence of metabolic syndrome in granite workers. $J$ Evid Based Med Hlthc. 2015;2(42):7341-5.

14. Hildrum B, Mykletun A, Hole T, Midthjell K, Dahl AA. Age-specific prevalence of the metabolic syndrome defined by the International Diabetes Federation and the National Cholesterol Education Program: the Norwegian HUNT 2 study. BMC Public Health. 2007;7:220.

15. Veronica G, Esther R. Aging, metabolic syndrome and the heart. Aging Dis. 2012;3(3):269-79.

16. Katsimardou A, Imprialos K, Stavropoulos K, Sachinidis A, Doumas M, Athyros V. Hypertension in Metabolic Syndrome: novel insights. Curr Hypertens Rev. 2019.

17. Mancia G, Bousquet P, Elghozi JL, Esler M, Grassi G, Julius S, et al. The sympathetic nervous system and the metabolic syndrome. $J$ Hypertens. 2007;25(5):909-20.

18. Rajapakse NW, Chong AL, Zhang WZ, Kaye DM. Insulin-mediated activation of the Larginine nitric oxide pathway in man, and its impairment in diabetes. PLoS One. 2013;8(5):e61840.

19. Oparil S, Acelajado MC, Bakris GL, Berlowitz DR, Cifkova R, Dominiczak AF, et al. Hypertension. Nat Rev Dis Primers. 2018;4:18014.

20. Tsushima $Y$, Nishizawa $H$, Tochino $Y$, Nakatsuji H, Sekimoto R, Nagao H, et al. Uric acid secretion from adipose tissue and its increase in obesity. $J$ Biol Chem. 2013;288(38):27138-49.

21. Cheung KJ, Tzameli I, Pissios P, Rovira I, Gavrilova O, Ohtsubo $\mathrm{T}$, et al. Xanthine oxidoreductase is a regulator of adipogenesis and PPARgamma activity. Cell Metab. 2007;5(2):115-28.

22. Kelley EE, Hock T, Khoo NK, Richardson GR, Johnson KK, Powell PC, et al. Moderate hypoxia induces xanthine oxidoreductase activity in arterial endothelial cells. Free Radic Biol Med. 2006;40(6):952-9.

23. Wang G, Qian P, Jackson FR, Qian G, Wu G. Sequential activation of JAKs, STATs and xanthine dehydrogenase/oxidase by hypoxia in lung microvascular endothelial cells. Int $J$ Biochem Cell Biol. 2008;40(3):461-70.

24. Tanaka K, Ogata S, Tanaka H, Omura K, Honda C, Osaka Twin Research G, et al. The relationship between body mass index and uric acid: a study on Japanese adult twins. Environ Health Prev Med. 2015;20(5):347-53.

25. Ford ES, Li C, Cook S, Choi HK. Serum concentrations of uric acid and the metabolic syndrome among US children and adolescents. Circulation. 2007;115(19):2526-32.

26. Mukhopadhyay $\mathrm{P}$, Ghosh S, Pandit K, Chatterjee P, Majhi B, Chowdhury S. Uric Acid and Its Correlation with Various Metabolic Parameters: A Population-Based Study. Indian $J$ Endocrinol Metab. 2019;23(1):134-9.

27. Cibičková L', Langová K, Vaverková $H$, Kubíčková V, Karásek D. Correlation of uric acid levels and parameters of metabolic syndrome. Physiol Res. 2017;66(3):481-7.

28. Matsuura F, Yamashita S, Nakamura T, Nishida M, Nozaki S, Funahashi $T$, et al. Effect of visceral fat accumulation on uric acid metabolism in male obese subjects: Visceral fat obesity is linked more closely to overproduction of uric acid than subcutaneous fat obesity. Metabolism. 1998;47(8):929-33.

29. Nejatinamini S, Ataie-Jafari A, Qorbani M, Nikoohemat S, Kelishadi R, Asayesh H, et al. Association between serum uric acid level and metabolic syndrome components. J Diabetes Metab Disord. 2015;14:70.

30. Cicerchi C, Li N, Kratzer J, Garcia G, RoncalJimenez CA, Tanabe $\mathrm{K}$, et al. Uric aciddependent inhibition of AMP kinase induces hepatic glucose production in diabetes and starvation: evolutionary implications of the uricase loss in hominids. FASEB $J$. 2014;28(8):3339-50.

31. Wei CY, Sun CC, Wei JC, Tai HC, Sun CA, Chung CF, et al. Association between Hyperuricemia and Metabolic Syndrome: An 
Epidemiological Study of a Labor Force Population in Taiwan. Biomed Res Int. 2015;2015:369179.

32. Nejatinamini S, Ataie-Jafari A, Qorbani M, Nikoohemat S, Kelishadi R, Asayesh H, et al. Association between serum uric acid level and metabolic syndrome components. J Diabetes Metab Disord. 2015;14(1):70.

33. Zhu Y, Hu Y, Huang T, Zhang Y, Li Z, Luo $\mathrm{C}$, et al. High uric acid directly inhibits insulin signalling and induces insulin resistance. Biochem Biophys Res Commun. 2014;447(4):707-14.

34. Kuwabara $\mathrm{M}$, Borghi $\mathrm{C}$, Cicero AFG, Hisatome I, Niwa K, Ohno M, et al. Elevated serum uric acid increases risks for developing high LDL cholesterol and hypertriglyceridemia: A five-year cohort study in Japan. Int J Cardiol. 2018;261:183-8.

35. Kanbay M, Jensen T, Solak Y, Le M, RoncalJimenez C, Rivard C, et al. Uric acid in metabolic syndrome: From an innocent bystander to a central player. Eur $J$ Intern Med. 2016;29:3-8.

36. Loeffler LF, Navas-Acien A, Brady TM, Miller ER, 3rd, Fadrowski JJ. Uric acid level and elevated blood pressure in US adolescents: National Health and Nutrition Examination Survey, 1999-2006. Hypertension. 2012;59(4):811-7.

37. Choi Y-J, Yoon Y, Lee K-Y, Hien TT, Kang $\mathrm{KW}$, Kim K-C, et al. Uric acid induces endothelial dysfunction by vascular insulin resistance associated with the impairment of nitric oxide synthesis. FASEB $J$. 2014;28(7):3197-204.

38. McMullan CJ, Borgi L, Fisher N, Curhan G, Forman J. Effect of Uric Acid Lowering on Renin-Angiotensin-System Activation and Ambulatory BP: A Randomized Controlled Trial. Clin J Am Soc Nephrol. 2017;12(5):80716.
39. Kim OY, Kwak SY, Kim B, Kim YS, Kim HY, Shin MJ. Selected Food Consumption Mediates the Association between Education Level and Metabolic Syndrome in Korean Adults. Ann Nutr Metab. 2017;70(2):122-31.

40. Silventoinen K, Pankow J, Jousilahti P, Hu G, Tuomilehto J. Educational inequalities in the metabolic syndrome and coronary heart disease among middle-aged men and women. Int J Epidemiol. 2005;34(2):327-34.

41. Roomi M, Mohammadnezhad M. Prevalence of metabolic syndrome among apparently healthy workforce. $J$ Ayub Med Coll Abbottabad. 2019;31(2):252-4.

42. Sun K, Liu J, Ning G. Active smoking and risk of metabolic syndrome: a meta-analysis of prospective studies. PLoS One. 2012;7(10):e47791.

43. Bergman BC, Perreault L, Hunerdosse D, Kerege A, Playdon M, Samek AM, et al. Novel and reversible mechanisms of smokinginduced insulin resistance in humans. Diabetes. 2012;61(12):3156-66.

44. Gual P, Le Marchand-Brustel Y, Tanti JF. Positive and negative regulation of insulin signaling through IRS-1 phosphorylation. Biochimie. 2005;87(1):99-109.

45. Huang JH, Li RH, Huang SL, Sia HK, Lee SS, Wang WH, et al. Relationships between different types of physical activity and metabolic syndrome among Taiwanese workers. Sci Rep. 2017;7(1):13735.

46. Wang N, Liu Y, Ma Y, Wen D. High-intensity interval versus moderate-intensity continuous training: Superior metabolic benefits in dietinduced obesity mice. Life Sci. 2017;191:12231.

47. Mann S, Beedie C, Jimenez A. Differential effects of aerobic exercise, resistance training and combined exercise modalities on cholesterol and the lipid profile: review, synthesis and recommendations. Sports Med. 2014;44(2):211-21. 